Biological and Clinical Sciences Research Journal

ISSN: 2708-2261

www.bcsrj.com

DOI: https://doi.org/10.54112/bcsrj.v2020i1.16

Biol. Clin. Sci. Res. J., Volume, 2020: 16

MEDEYE

Original Research

\title{
EVALUATION OF GENETIC VARIABILITY FOR SALT TOLERANCE IN WHEAT
}

\author{
IQRA L ${ }^{1}$, RASHID MS $^{1},{ }^{*} A L I Q^{1}$, LATIF I ${ }^{2}$, MALIK A ${ }^{1}$ \\ ${ }^{1}$ Institute of Molecular Biology and Biotechnology, University of Lahore, Lahore Pakistan \\ ${ }^{2}$ Soil and Water Testing Laboratory, Lahore, Pakistan \\ *Corresponding author email: saim1692@gmail.com
}

(Received, $5^{\text {th }}$ April 2020, Revised $29^{\text {th }}$ June 2020, Published $17^{\text {th }}$ July 2020)

\begin{abstract}
Wheat is an important cereal crop which has been consumed as food crop throughout the globe. Present study discusses change in different morphological traits of six most common wheat varieties in Pakistan under the effect of salt stress. We have used two salt solutions; $10 \mathrm{dS} / \mathrm{m} \mathrm{NaCl}$ and $15 \mathrm{dS} / \mathrm{m} \mathrm{NaCl}$ concentrations were used in our research. Data collected during research indicates that all morphological traits decrease under salt treatments except that of two trait viz., root length and carotenoids level. It was noted that under the effect of both salt concentrations carotenoids content increased in significant amount in leaves and roots along with root length which was also increased. The outcomes from analysis of variance demonstrated that there was higher leaf caroteniods for genotype 5 (Ujala-16) that was $998.32 \mathrm{mg} / \mathrm{g}$ of fresh leaf weight trailed by genotype 1 (Inqalab-91) $995.99 \mathrm{mg} / \mathrm{g}$ of fresh leaf weight) while lower carotenoids were found for genotype 2(Shafaq-06) that was $825.65 \mathrm{mg} / \mathrm{g}$ of fresh leaf weight. Highest root weight was found in Shafaq-06 under treatment of $15 \mathrm{dS} / \mathrm{m} \mathrm{NaCl}$. While pooled all Pairwise comparison test revealed highest root length in genotype 4 (Galaxy-13). While linear regression suggests that carotenoids content contribute least in plant height. Genetic heritability was found highest for photosynthetic pigments i.e. $99.99 \%$ for chlorophyll b except that of carotenoids. Genetic advance was recorded higher for fresh stem weight (309.870\%). Higher heritability and genetic advance revealed that from our study that the selection of salt stress wheat genotypes on the basis of root length may be help to develop salt stress tolerance wheat genotypes with higher grain yield.
\end{abstract}

Keywords: salinity, wheat, $\mathrm{NaCl}$, carotenoid content, genetic advance, broad sense heritability

\section{Introduction}

The king of cereal wheat belongs to poaceace family. It is a staple food of Pakistan. Total area of wheat cultivation in the world is about 13.4 billion hectares. Wheat is the most cultivated crop of the world and according to a report of 2014 it is grown on 220 million hectares worldwide. It is growing all over the globe and is second most growing crop after corn. Wheat was first ever cultivated by some 10,000 years ago during Neolithic revolution (Shewry, 2009). Enkiron and tetraploid was ever cultivated wheat (Hirzel et al., 2018). Wheat is most consumable food across the world as well. Gluten protein is present in wheat flour that helps to make roti. It has sticky powers. China is the world largest wheat producing country. In Pakistan 40\% land area is consumed for wheat production. In Punjab, Pakistan wheat is grown on 6.97 million hector area that is $75 \%$ of the total wheat production. In Sindh Wheat is grown on 1.15 million hectares that is $12 \%$. In KPK 0.73 million hectares i.e. $8 \%$ and Baluchistan with 0.38 million hectares (4\% of total wheat production of Pakistan) is reserved for wheat production (Haider et al., 2019).
According to an agricultural report Faisalabad 2008 and Sehar 2006 is most dominating wheat variety in Punjab almost $50 \%$ of the total area. Pakistan has also more than 30 wheat verities; each variety has its own requirement of water and nutrients (Abid et al., 2014; Mohsin et al., 2015; Raza et al., 2012). In my research Salinity condition in Pakistan is not different from the world as 6.30 million hectares out of 21.2 million hectares total cultivated area is affected by salinity. Out of this 1.89 million hectares are saline, 1.85 million hectares is permeable saline-sodic, 1.02 million hectares impermeable saline-sodic and 0.028 million hector is sodic. Deposition of salts in soil is salinity. Saline and saline sodic are the categories of salt containing soils with different amount of salts. Salts may be deposit by irrigation water. Different physiological stresses lay different sensitivity effects on plant growth (Gao et al., 2016; Zubair et al., 2016). According to a study hexaploid wheat is more salt tolerant than to its wild relative tetraploid but physiology is not clear that how this is possible (Yang et al., 2014). Due to less variation in genetic makeup plants show more salt tolerance (Oladosu et al., 2016). Salt reduces the photosynthetic ability of 
plants (Ali et al., 2015; Aly et al., 2018). As wheat is staple food of Pakistan. And salinity is increasing day by day so this problem will be severe. It's my estimation that in next 50 years salinity rate will be double and yield of wheat will be reduced that will lead to starvation. During my research I also found clear-cut morphological differences in both control and affected plants. Affected Leaves showed yellowing and brown margins. In developing countries it is very difficult to provide clean water to crops. Recently saffron can also be used in order to remove soil salinity (Sereshti et al., 2018).

\section{Materials and method}

The present study was conducted in institute of molecular biology and biotechnology at university of Lahore, Lahore (Pakistan). For this purpose seeds of six wheat verities Inqalab-91, Shafaq-06, Faisalabad08, Galaxy-13, Ujala-16 and Anaj-17 with different genetic makeup and origin were collected from Ayub Agriculture Research Institute, Faisalabad.

\subsection{Assessment of wheat germplasm at seedling stage:}

Seeds of six varieties with different origin Inqalab91, Shafaq-06, Faisalabad-08, Galaxy-13, Ujala-16 and Anaj-17 were grown in three different situations. Two salt solutions i.e. $10 \mathrm{dS} / \mathrm{m} \mathrm{NaCl}$ and $15 \mathrm{dS} / \mathrm{m}$ were prepared for salt treatment.

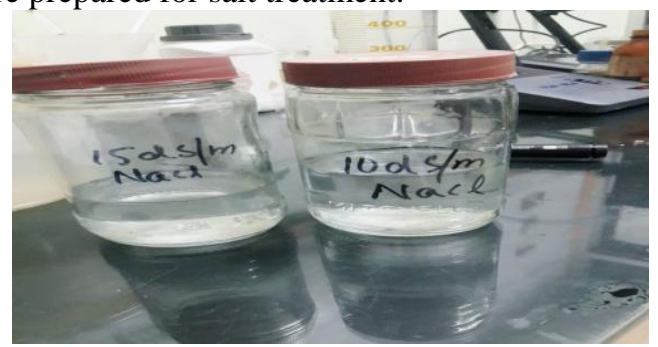

Fig I: Salt solutions of two different concentration i.e. $10 \mathrm{dS} / \mathrm{m}$ and $15 \mathrm{dS} / \mathrm{m}$ used for treatment

First step was seed priming. For this seeds were dipped in tap water for two hours and then surface sterilized the seeds by adding $2 \% \mathrm{v} / \mathrm{v}$ commercial bleach for three minutes. After that seeds were rinsed with distilled water three times. Seeds were soaked on watman paper. Some other methods include treatment of seeds with $5 \%$ sodium hypochlorite for
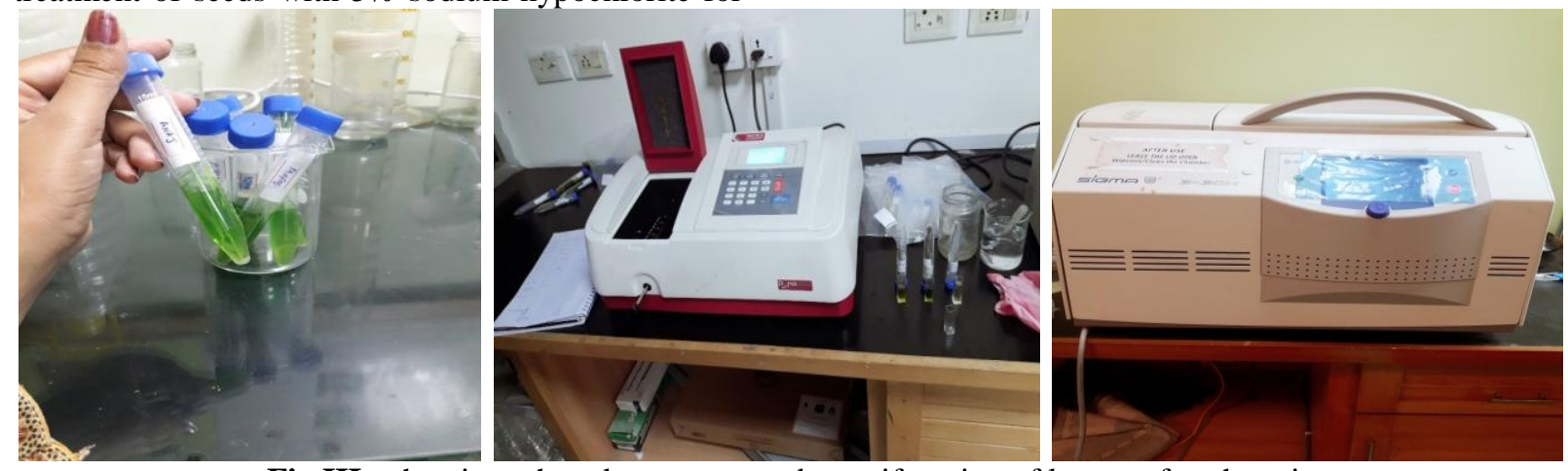

Fig III: showing ethanol treatment and centrifugation of leaves of each variety

[Citation: Iqra, L., Rashid, M.S., Ali, Q., Latif, I., Malik A. (2020). Evaluation of genetic variability for salt tolerance in wheat. Biol. Clin. Sci. Res. J. Volume, 2020: 16 doi: https://doi.org/10.54112/bcsrj.v2020i1.16] 


\subsection{Statistical analysis of Morphological traits for} salt tolerance

Ordinary analysis of variance followed by Tukey's range test was applied on all morphological traits to find out the genotypic differences between all accessions is significant or not (Zahra et al., 2018). General linear model of SPSS version 23 windows advance was used.

\subsection{Correlation Analysis}

By using SPSS version 23.1correlation was calculated between all morphological traits under salt treatment. All the morphological traits showed positive and negative significant correlation with one another.

2.5 Broad sense heritability $\left(h^{2} b . s\right)$ for salt tolerance Broad sense heritability was analyzed for all morphological traits of all accessions under salt stress. Variance within varieties calculated by a formula given by (Falconer and Mackay, 1996). Variance between accessions is due to environmental factors, as wheat is self pollinated crop.

\section{3-Results and discussion}

\subsection{Carotenoids in leaves $(\mathrm{mg} / \mathrm{g}$ fresh leaf weight)}

It was convinced from results given in table 3.1 (given in supplementary data) that there were critical contrast among wheat genotypes, salt treatment and associations among genotypes and salt treatments. It was discovered that the normal caroteniods in average were $997.69 \pm 6.760 \mathrm{mg} / \mathrm{g}$ of leaf weight in wheat seedlings under treatment of salt solutions. It was discovered that there was exceptionally low coefficient of variance $(0.001 \%)$ for carotenoids in leaves showed that there was higher consistency for carotenoids in leaves. The outcomes from table 3.1a (given in supplementary data) demonstrated that there was higher leaf caroteniods for genotype 5 ( $998.32 \mathrm{mg} / \mathrm{g}$ new leaf weight) trailed by genotype 1 (995.99 mg/g fresh leaf weight) while lower carotenoids were found for genotype $3(851.86 \mathrm{mg} / \mathrm{g}$ new leaf weight $)$ and genotype $2(825.65 \mathrm{mg} / \mathrm{g}$ new leaf weight). The higher leaf carotenoids showed that there were higher photosynthetic pigments in the leaves which might be useful for the improvement of natural pigments in the leaves and gives obstruction against different abiotic stresses. The higher leaf carotenoids in genotype 5 demonstrated that there was higher obstruction and survival capacity under salt treatments. The treatment of salt caused higher harming consequences for genotypes 2 and 3 . The genotypes which demonstrated higher leaf carotenoids might be chosen as salt tolerant genotypes in wheat. It was influenced from figure 4.1 (given in supplementary data) that there were little contrasts among the genotypes under treatments of salt solutions. The outcomes demonstrated that the majority of the genotypes indicated comparable sort of leaf carotenoids under salt treatments. Be that as it may, the collective effects of salt treatments for every genotype were distinctive as depicted by results in table 3.1 and 3.1a (given in supplementary data).

\subsection{Root Length $(\mathbf{c m})$}

Table 3.2(given in supplementary data) clearly indicates that there is difference between root lengths of wheat seedlings. Table shows there is significant difference between genotypes and salt treatments. It is clear from the table 3.2 that there is average of $8.9581 \pm 0.1218 \mathrm{~cm}$ of Root length of wheat seedling. Table 3.2a (given in supplementary data) shows that higher leaf diameter was found in genotype 4 $(12.993 \mathrm{~cm})$ followed by genotype $1(8.800 \mathrm{~cm})$ of wheat seedling. While lowest root length was recorded in genotype $5(7.890 \mathrm{~cm})$ and genotype 2 $(7.081 \mathrm{~cm})$. In simple words we can say that genotype 1 and genotype 4 has showed more resistance to salt solutions. On the other hand genotype 5 and 2 are more affected under salt treatments. It is clear from figure 3.2 (given in supplementary data) that there are differences in root length among the genotypes under salt treatment. The results showed the differences in root length in all genotypes of wheat seedlings when exposed to $10 \mathrm{dS} / \mathrm{m} \mathrm{NaCl}$ and $15 \mathrm{dS} / \mathrm{m} \mathrm{NaCl}$. However, the collective effects of salt treatments for every genotype was distinctive are given by results in table 3.2 and 3.2a (given in supplementary data) in more detail. Salinity reduces photosynthetic pigments but increase only in carotenoids which cause increase in root length a little bit among all other morphological traits (Latef et al., 2017).

\subsection{Plant Height (cm)}

Table 3.3(given in supplementary data) clearly indicates that there is difference between plant heights of wheat seedlings. Table shows there is significant difference between genotypes and salt treatments. It is clear from the table 3.3 that there is average of $7.3729 \pm 0.0517 \mathrm{~cm}$ of plant height of wheat seedling. Table 3.3 a(given in supplementary data) shows that higher leaf diameter was found in genotype $1(9.18 \mathrm{~cm})$ followed by genotype 3 $(8.48 \mathrm{~cm})$ of wheat seedling. While lowest plant height was recorded in genotype $5(6.50 \mathrm{~cm})$ and genotype $6(5.90 \mathrm{~cm})$. In simple words we can say that genotype 1 and genotype 3 has showed more resistance to salt solutions. On the other hand genotype 5 and 6 are more affected under salt treatments. It is clear from figure 3.3 (given in supplementary data) that there are differences in plant height among the genotypes under salt treatment. The results showed the differences in plant height in all genotypes of wheat seedlings when exposed to $10 \mathrm{dS} / \mathrm{m} \mathrm{NaCl}$ and $15 \mathrm{dS} / \mathrm{m} \mathrm{NaCl}$. However, the collective effects of salt treatments for every genotype was distinctive are given by results in table 3.3 and 3.3a (given in supplementary data) in more detail. 


\subsection{Correlation Analysis}

Results from table 3.4 clearly shows that there is positive and significant correlation between wheat seedling carotenoids and fresh leaf weight( FLW), fresh root weight(FRW), fresh stem weight(FSW) and root length(RL). While negative but significant correlation was found with chlorophyll a, chlorophyll $\mathrm{b}$, leaf diameter (LD), leaf length(LL), plant height $(\mathrm{PH})$ and shoot diameter (SD). Positive correlation with root length shows that under stressed condition when there is deposition of carotenoids in root, stem and leaf plant try to survive and in this way they increase their root length. Off course with the increase in carotenoids there is positive correlation with stem, leaf and root weight under salt treatment. Previous study also indicates there is considerable increase in carotenoids and other phenolic compounds i.e. beta-carotenoids, lutin, $\beta$ solamargine and caffeic acid under $10 \mathrm{dS} / \mathrm{m} \mathrm{Nacl}$ solution. Infect increased content of carotenoid genes can be found significantly under salinity (BenAbdallah et al., 2018). According to table 3.4 chlorophyll.a has positive and significant correlation with chlorophyll b and leaf diameter (LD) while negative but significant correlation with caroteniods, fresh leaf weight (FLW), fresh root weight (FRW), fresh stem weight (FSW) and root length (RL). Negative correlation with carotenoids shows that if there is increase in carotenoids content which is obvious during salt stress then amount of chlorophyll start decreasing in plant seedling as given in past salinity research too (Ali et al., 2013; Piñero Zapata et al., 2019). According to table 3.4chlorophyll.b has positive and significant correlation with chlorophyll $\mathrm{b}$, shoot diameter (SD) and leaf diameter (LD) while negative but significant correlation with caroteniods, fresh leaf weight (FLW), fresh root weight (FRW), fresh stem weight (FSW), and root length (RL). Negative correlation with carotenoids shows that if there is increase in carotenoids content which is obvious during salt stress then amount of chlorophyll start decreasing in plant seedling. Higher level of salinity caused degradation of chlorophyll b content in young seedling (Monteiro et al., 2018). Table 3.4 shows that plant height has positive, higher and significant correlation with chlorophyll a, b, stem weight, leaf diameter and leaf length. On the other hand significant negative correlation with carotenoids, leaf weight and root weight. A well know salt tolerant plant safflower also shows reduction in plant height because during salt stress a lot of secondary metabolites (Ali et al., 2014b; Ali et al., 2014c; Gengmao et al., 2015). Salinization cause increase in carotenoids in root, stem and leaves at dangerous level that cause reduction in plant height and stunt growth at seedling stage (Masood et al., 2014a; Serra et al., 2018). Shoot diameter shares significant correlation with root diameter is evidence that there is higher level of organic compounds aggregation in seedling under salt stress; salinity reduces the plant growth rates at seedling stage(Sallaku et al., 2019). When there is higher level of salt in plant seedling roots there is always negative relation between caroteniods and chlorophyll.a and chlorophyll.b (Ali et al., 2017; Vahtmäe et al., 2018). Table 3.4 shows that there is considerable, positive and significant correlation between root length and carotenoids and root weight. Whereas negative but significant correlation with chlorophyll $\mathrm{a}$ and $\mathrm{b}$ and plant height. As plant feels stress under salinity first and foremost response of plant seedling is to increase its root length. Carotenoids content is directly related to root length, simply we can say that increase in carotenoid increases root length. Salinity reduces photosynthetic pigments but increase only in carotenoids which cause increase in root length a little bit among all other morphological traits (Latef et al., 2017; Masood et al., 2014c; Naseem et al., 2015). Table 3.4 shows that plant height has positive, higher and significant correlation with chlorophyll a, $b$, stem weight, leaf diameter and leaf length. On the other hand significant negative correlation with carotenoids, leaf weight and root weight. A well know salt tolerant plant safflower also shows reduction in plant height because during salt stress a lot of secondary metabolites (Gengmao et al., 2015). Salinization cause increase in carotenoids in root, stem and leaves at dangerous level that cause reduction in plant height and stunt growth at seedling stage (Raza et al., 2015; Serra et al., 2018).
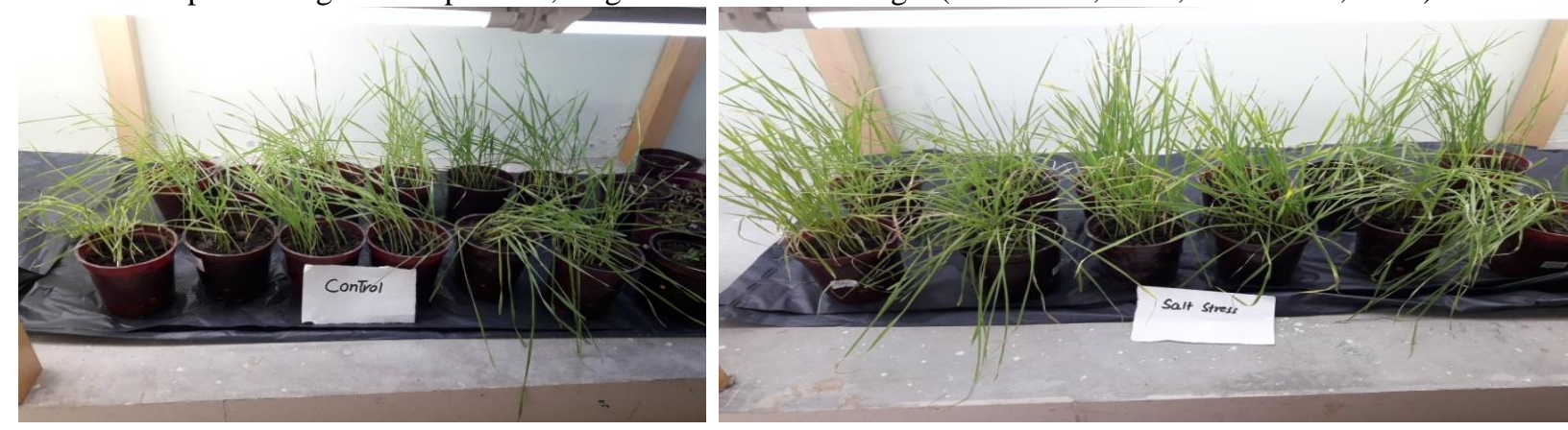

Fig IV: All six verities with and without salt treatment

[Citation: Iqra, L., Rashid, M.S., Ali, Q., Latif, I., Malik A. (2020). Evaluation of genetic variability for salt tolerance in wheat. Biol. Clin. Sci. Res. J. Volume, 2020: 16 doi: https://doi.org/10.54112/bcsrj.v2020i1.16] 
Table 3.4: Pooled correlation among different morphological traits of wheat seedlings under salt treatments

\begin{tabular}{|c|c|c|c|c|c|c|c|c|c|c|c|}
\hline $\begin{array}{l}\text { Traits } \\
\text { Chla }\end{array}$ & $\begin{array}{l}\text { Carotenoids } \\
-0.997^{*}\end{array}$ & Chla. & Chlb. & FLW & FRW & FSW & LD & LL & PH & RD & $\mathbf{R L}$ \\
\hline Chlb & $-0.9188^{*}$ & $0.9182^{*}$ & & & & & & & & & \\
\hline FLW & $0.2954 *$ & $-0.2951^{*}$ & $-0.355^{*}$ & & & & & & & & \\
\hline FRW & 0.0219 & -0.0208 & $-0.3181 *$ & $0.2879 *$ & & & & & & & \\
\hline FSW & $0.3349^{*}$ & $-0.3351^{*}$ & $-0.2585^{*}$ & $0.8714 *$ & 0.0282 & & & & & & \\
\hline LD & -0.1254 & 0.1254 & 0.1005 & $-0.3587 *$ & -0.1777 & $-0.2562 *$ & & & & & \\
\hline $\mathbf{L L}$ & -0.1868 & 0.187 & 0.1092 & 0.0606 & $0.2073 *$ & -0.0322 & $-0.4884^{*}$ & & & & \\
\hline PH & $-0.2308 *$ & $0.2305^{*}$ & $0.2941^{*}$ & -0.1848 & -0.1356 & 0.0586 & 0.158 & 0.0553 & & & \\
\hline RD & $-0.4549 *$ & $0.4554^{*}$ & $0.305^{*}$ & -0.1551 & $0.2567 *$ & -0.1173 & $0.5569 *$ & 0.0698 & $0.2455^{*}$ & & \\
\hline RL & $0.4327 *$ & $-0.4328^{*}$ & $-0.3951^{*}$ & -0.0673 & 0.105 & -0.05 & $-0.2541^{*}$ & 0.0512 & $-0.4008^{*}$ & -0.0808 & \\
\hline SD & $-0.5579 *$ & $0.5574 *$ & $0.6201 *$ & $-0.6823^{*}$ & $-0.5423^{*}$ & $-0.5909 *$ & $0.3851 *$ & -0.0802 & -0.0722 & 0.1488 & -0.0963 \\
\hline
\end{tabular}

$*=$ Significant at $5 \%$ probability level Ch.a=Chlorophyll.a, FLW=Fresh leaf weight, FRW=Fresh root weight, FSW=Fresh stem weight, $\mathrm{LD}=$ leaf diameter, $\mathrm{LL}=$ leaf length, $\mathrm{RD}=$ root diameter, $\mathrm{RL}=$ root length, $\mathrm{SD}=$ shoot diameter, Ch.b=chlorophyll $b$

\subsection{Regression Analysis}

Table 3.5 showing regression data was taken for twelve variables contributing to plant height. Regression analysis is showing that leaf carotenoids (1212.7) have higher and negative contribution for plant height under salt stress. This is because when there is salt stress there is increase in accessory photosynthetic pigments and increase in root length. On the same pace rapid decrease I necessary photosynthetic pigments cause decrease in plant height. While the other variables shows less contribution towards plant height. Previous studies on wheat regression was also conducted to find out different variables contribution towards wheat grain yield and plant height such as (Ali et al., 2014a; Leilah and Al-Khateeb, 2005; Mahmood et al., 2019) used this stepwise regression model to find out the weight of grain, harvest index, biological yield and spike length. Another study also shows the same as found in my results that carotenoids are significantly contributing towards phenotypic variations in plants under stress and specific genes are controlling this mechanism (Chander et al., 2008; Farooq et al., 2011). The data of table 3.5 represents accumulative medium coefficient of determination or $\mathrm{R}^{2}$ for plant height and lower coefficient of determination or $\mathrm{R}^{2}$ $(0.07022 \%)$ that was found for leaf carotenoids. The regression equation was written as following:

$\mathrm{Y}=1212710-1212.7$ (caroteniods) +1213.21 (Ch.a) + 0.12636 (FLW)-0.79724(FRW)-2.10036(FSW)

2.5479(LD)+0.1882(LL)-3.43352(RD) $-0.10799(\mathrm{RL})$ -4.20165 (SD) +1.000 (ch.b).

Table 3.5 : Pooled stepwise linear regression for plant height or seedling length under different salt treatments

\begin{tabular}{lllll}
\hline Variable & Coefficient & Std Error & T & $\mathbf{R}^{2}$ \\
Carotenoids & -1212.7 & 649.896 & -1.87 & 0.07022 \\
Chl. A & 1213.21 & 652.693 & -1.86 & 0.07122 \\
FLW & 0.12636 & 1.22911 & 0.1 & 0.9187 \\
FRW & -0.79724 & 0.69081 & -1.15 & 0.2561 \\
FSW & -2.10036 & 1.3668 & -1.54 & 0.1331 \\
LD & -2.5479 & 2.63942 & -0.97 & 0.3408 \\
LL & 0.1882 & 0.03632 & 5.18 & 0 \\
RD & -3.43352 & 1.47699 & -2.32 & 0.0258 \\
RL & -0.10799 & 0.0371 & -2.91 & 0.0061 \\
SD & -4.20165 & 1.16768 & -3.6 & 0.001 \\
Chl. B & 1.000 & -0.0973 & -0.58 & 0.5667 \\
\hline
\end{tabular}

$\mathrm{Y}=1212710, \mathrm{R}^{2}=0.9251, \quad$ Adjusted $\mathrm{R}^{2}=0.9022 \%$, Standard Deviation $=0.45948$, Ch.a=Chlorophyll.a, FLW=Fresh leaf weight, FRW=Fresh root weight, FSW=Fresh stem weight, $L D=$ leaf diameter, LL=leaf length, $\mathrm{RD}=$ root diameter, $\mathrm{RL}=$ root length, $\mathrm{SD}=$ shoot diameter, $\mathrm{Ch} . \mathrm{b}=$ chlorophyll $\mathrm{b}$

3.6 Broad sense heritability for wheat seedling

Table 3.6 shows that there are considerable differences among all the morphological traits of wheat. Highest broad sense heritability was found for the Chlorophyll b (99.994\%), Root length (99.747\%), fresh leaf weight $(99.961 \%)$, root diameter $(99.426 \%)$ traits. Lowest broad sense heritability is found for leaf length $(79.546 \%)$ and carotenoids $(55.456 \%)$. 
While genetic advance in carotenoids is $(0.016 \%)$ contrary to this maximum found in chlorophyll $\mathrm{b}$ $(101.049 \%)$.This is all due to change in environmental factors leads to changes in varieties. In current study broad sense heritabilities in wheat are quiet high as compared to all other species i.ie maize and four grass families studied by different researchers (Akbar et al., 2008; Masood et al., 2014b). Present values for genetic heritability shows variation for root length, root weight and photosynthetic pigments under treatment of two solutions $10 \mathrm{dS} / \mathrm{m}$ and $15 \mathrm{dS} / \mathrm{m} \mathrm{NaCl}$. These variations are due to variation in genetics of wheat germplasm. Environmental factors, accumulation of different ions and breeding plays a significant role in determing genetic heritability under salt treatment.

Table 3.6 Pooled Genetic components for various morphological traits of wheat seedling

\begin{tabular}{lllllllllll}
\hline Traits & M.S & G.M \pm S.E & GV & GCV \% & PV & PCV \% & EV & ECV \% & $h^{2} b s \%$ & GA\% \\
Carotenoids & 0.057 & $999.690 \pm 6.760$ & 0.015 & 0.388 & 0.027 & 0.521 & 0.01207 & 0.347 & 55.456 & 0.016 \\
ch.a & 0.066 & $0.300 \pm 6.747$ & 0.022 & 27.033 & 0.022 & 27.144 & 1.82 & 2.449 & 99.186 & 86.265 \\
ch.b & 0.075 & $0.274 \pm 6.366$ & 0.025 & 30.135 & 0.025 & 30.136 & $1.62 \mathrm{E}-06$ & 0.242 & 99.994 & 101.049 \\
FLW & 0.383 & $0.203 \pm 3.505$ & 0.128 & 79.400 & 0.128 & 79.416 & 0.00005 & 1.571 & 99.961 & 309.523 \\
FRW & 0.202 & $0.425 \pm 3.505$ & 0.067 & 39.657 & 0.068 & 40.141 & 0.30241 & 6.213 & 97.604 & 105.496 \\
FSW & 0.180 & $0.138 \pm 9.986$ & 0.060 & 65.810 & 0.060 & 66.030 & 0.0004 & 5.384 & 99.335 & 309.870 \\
LD & 0.015 & $0.073 \pm 4.931$ & 0.005 & 24.958 & 0.006 & 27.488 & 9.726 & 11.519 & 82.439 & 146.892 \\
RD & 0.047 & $0.071 \pm 4.611$ & 0.016 & 46.831 & 0.016 & 46.966 & 0.00009 & 3.558 & 99.426 & 307.346 \\
RL & 34.389 & $8.958 \pm 0.1218$ & 11.443 & 113.023 & 11.502 & 113.314 & 0.059 & 8.116 & 99.487 & 66.103 \\
PH & 12.650 & $7.737 \pm 0.0517$ & 4.213 & 75.593 & 4.224 & 75.689 & 0.0107 & 3.810 & 99.747 & 48.796 \\
SD & 0.127 & $0.469 \pm 0.0234$ & 0.042 & 29.809 & 0.044 & 30.578 & 0.00218 & 6.815 & 95.033 & 74.437 \\
LL & 19.333 & $39.383 \pm 0.6177$ & 5.936 & 38.822 & 7.462 & 43.528 & 1.526 & 19.686 & 79.546 & 9.683 \\
\hline
\end{tabular}

*=Significant at 5\% probability level, Mean Sum of Squares (M.S), Grand mean (G.M), Genotypic variance (GV), Genotypic coefficient of variance (GCV \%), Phenotypic variance (PV), Phenotypic coefficient of variance (PCV \%), Environmental Variance (EV), Environmental coefficient of variance (ECV \%), Broad sense heritability (h ${ }^{2}$ bs $\%$ ), Genetic advance (GA), Chlorophyll a(ch.a), Chlorophyll b(ch.b), Fresh leaf weight(FLW), Fresh root weight(FRW), Fresh stem weight(FSW), Leaf diameter(LD), Root diameter(RD), Root length(RL), Plant height(PH), Stem diameter(SD), Leaf length(LL).

\section{4- Conclusions}

For our study For this purpose seeds of six different wheat varieties with totally different genetic makeup and origin were selected. Main purpose of this investigation was to collect information to estimate genetic response of wheat genotypes in respect of salinity at seedling stage. For every morphological trait every genotype showed significant differences from each other, this means that they have different genetic makeup and so the genes response to salinity. On the basis of mean root length given in most stable wheat genotype was Faisalabad-08, which is also the variety that is grown on $50 \%$ in the Punjab agricultural land. Concluding my investigation; it was just analysis of different morphological traits of most used wheat varieties of Punjab, Pakistan under the effect of two salt solutions, how do they differ from each other because of their different genetic response to salt stress. So need of hour is we have to make our crops more tolerant and resistant against salinity. Further research is needed to analyze the genetic components, study on genes that may assist wheat plant to cope with salinity.

\section{Conflict of interest}

The authors declared the absence of any potential conflict of interest.

\section{References}

Abid, N., Maqbool, A., and Malik, K. A. (2014). Screening commercial wheat (Triticum aestivum
L.) varieties for Agrobacterium mediated transformation ability. Pakistan Journal of Agricultural Sciences $\mathbf{5 1 .}$

Akbar, M., Shakoor, M. S., Hussain, A., and Sarwar, M. (2008). Evaluation of maize 3-way crosses through genetic variability, broad sense heritability, characters association and path analysis. Journal of Agricultural Research (Pakistan).

Ali, F., Ahsan, M., Ali, Q., and Kanwal, N. (2017). Phenotypic stability of Zea mays grain yield and its attributing traits under drought stress. Frontiers in plant science 8, 1397.

Ali, F., Kanwal, N., Ahsan, M., Ali, Q., Bibi, I., and Niazi, N. K. (2015). Multivariate analysis of grain yield and its attributing traits in different maize hybrids grown under heat and drought stress. Scientifica 2015.

Ali, Q., Ahsan, M., Ali, F., Ali, A., Kanwal, N., Naseem, Z., Zahid, K. R., Nasir, I. A., and Husnain, T. (2014a). Genetic correlation and hybrid vigor for physiological traits of Zea mays. Nat Sci 12, 50-59.

Ali, Q., Ahsan, M., Ali, F., Aslam, M., Khan, N. H., Munzoor, M., Mustafa, H. S. B., and Muhammad, S. (2013). Heritability, heterosis and heterobeltiosis studies for morphological traits of maize (Zea mays L.) seedlings. Advancements in Life sciences $\mathbf{1 .}$ 
Ali, Q., Ali, A., Ahsan, M., Nasir, I. A., Abbas, H. G., and Ashraf, M. A. (2014b). Linex Tester analysis for morpho-physiological traits of Zea mays L seedlings. Advancements in Life sciences 1, 242-253.

Ali, Q., Ali, A., Awan, M. F., Tariq, M., Ali, S., Samiullah, T. R., Azam, S., Din, S., Ahmad, M., and Sharif, N. (2014c). Combining ability analysis for various physiological, grain yield and quality traits of Zea mays L. Life Sci J 11, 540-551.

Aly, A. A., Maraei, R. W., and Ayadi, S. (2018). Some biochemical changes in two egyptian bread wheat cultivars in response to gamma irradiation and salt stress. Bulgarian Journal of Agricultural Science 24, 50-59.

Ben-Abdallah, S., Zorrig, W., Amyot, L., Renaud, J., Hannoufa, A., Lachâal, M., and KarrayBouraoui, N. (2018). Potential production of polyphenols, carotenoids and glycoalkaloids in Solanum villosum Mill. under salt stress. Biologia, 1-16.

Chander, S., Guo, Y., Yang, X., Zhang, J., Lu, X., Yan, J., Song, T., Rocheford, T., and Li, J. (2008). Using molecular markers to identify two major loci controlling carotenoid contents in maize grain. Theoretical and Applied Genetics 116, 223-233.

Falconer, D., and Mackay, T. (1996). Heritability. Introduction to quantitative genetics, 160-183.

Farooq, J., Khaliq, I., Ali, M. A., Kashif, M., Rehman, A. U., Naveed, M., Ali, Q., Nazeer, W., and Farooq, A. (2011). Inheritance pattern of yield attributes in spring wheat at grain filling stage under different temperature regimes. Australian Journal of Crop Science 5, 1745.

Gao, Y., Lu, Y., Wu, M., Liang, E., Li, Y., Zhang, D., Yin, Z., Ren, X., Dai, Y., and Deng, D. (2016). Ability to remove $\mathrm{Na}+$ and retain $\mathrm{K}+$ correlates with salt tolerance in two maize inbred lines seedlings. Frontiers in plant science 7, 1716.

Gengmao, Z., Yu, H., Xing, S., Shihui, L., Quanmei, S., and Changhai, W. (2015). Salinity stress increases secondary metabolites and enzyme activity in safflower. Industrial crops and products 64, 175-181.

Ghanbari, M., Modarres-Sanavy, S. A. M., and Mokhtassi-Bidgoli, A. (2018). Germination Characteristics and Seed Activity of Enzymes of Different Landraces of Indian Cheese Maker (Withania coagulans) in Response to Sodium Hypochlorite and Pre-chilling. Iranian Journal of Seed Research 5, 119-135.

Haider, S. A., Naqvi, S. R., Akram, T., Umar, G. A., Shahzad, A., Sial, M. R., Khaliq, S., and Kamran, M. (2019). LSTM neural network based forecasting model for wheat production in Pakistan. Agronomy 9, 72.

Hirzel, J., Retamal-Salgado, J., Walter, I., and Matus, I. (2018). Effect of soil cadmium concentration on three Chilean durum wheat cultivars in four environments. Archives of Agronomy and Soil Science 64, 162-172.

Kodikara, K. A. S., Jayatissa, L. P., Huxham, M., Dahdouh-Guebas, F., and Koedam, N. (2018). The effects of salinity on growth and survival of mangrove seedlings changes with age. Acta Botanica Brasilica 32, 37-46.

Latef, A. A. H. A., Alhmad, M. F. A., and Abdelfattah, K. E. (2017). The possible roles of priming with $\mathrm{ZnO}$ nanoparticles in mitigation of salinity stress in lupine (Lupinus termis) plants. Journal of plant growth regulation 36, 60-70.

Leilah, A., and Al-Khateeb, S. (2005). Statistical analysis of wheat yield under drought conditions. Journal of Arid environments 61, 483-496.

Mahmood, A., Ali, Q., Ahmad, S., Bakhsh, A., Mahpara, S., Kamaran, S., Mamoon-Ur-Rashid, M., Salman, S., Waseem, M., and Haider, M. (2019). Genetic potential and association among morpho-physiological traits of petunia inbred lines. Applied Ecology and Environmental Research 17, 7311-7332.

Masood, S. A., Ahmad, S., Kashif, M., and Ali, Q. (2014a). Correlation analysis for grain and its contributing traits in wheat (Triticum aestivum L.). Nat Sci 12, 168-176.

Masood, S. A., Ahmad, S., Kashif, M., and Ali, Q. (2014b). Role of combining ability to develop higher yielding wheat (Triticum aestivum L.) genotypes: An overview. Natural Sciences 12, 155-161.

Masood, S. A., Ali, Q., and Abass, H. (2014c). Estimation of general and specific combining ability for grain yield traits in Triticum aestivum. Nat Sci 12, 191-198.

Mohsin, S., Malik, K. A., and Maqbool, A. (2015). Comparison of phytase activity in roots of wheat varieties grown under different phosphorus conditions. Research in Biotechnology 6.

Monteiro, D. R., Melo, H. F. d., Lins, C. M., Dourado, P. R., Santos, H. R., and Souza, E. R. d. (2018). Chlorophyll a fluorescence in saccharine sorghum irrigated with saline water. Revista Brasileira de Engenharia Agrícola e Ambiental 22, 673-678.

Naseem, Z., Masood, S. A., Irshad, S., Annum, N., Bashir, M. K., Anum, R., Qurban, A., Arfan, A., Naila, K., and Nazar, H. (2015). Critical study of gene action and combining ability for varietal development in wheat: An Overview. Life Sci J 12, 104-108. 
Oladosu, Y., Rafii, M. Y., Abdullah, N., Hussin, G., Ramli, A., Rahim, H. A., Miah, G., and Usman, M. (2016). Principle and application of plant mutagenesis in crop improvement: a review. Biotechnology \& Biotechnological Equipment 30, 1-16.

Piñero Zapata, M. C., Porras, M., López-Marín, J., Sánchez-Guerrero, M. C., Medrano, E., Lorenzo, P., and Del Amor, F. M. (2019). Differential nitrogen nutrition modifies polyamines and the amino-acid profile of sweet pepper under salinity stress. Frontiers in Plant Science 10, 301.

Raza, M. A., Ahmad, H. M., Akram, Z., and Ali, Q. (2015). Performance evaluation of wheat (Triticum aestivum L.) genotypes for physiological and qualitative traits. Life Science Journal 12.

Raza, S., Saleem, M., Khan, I., Jamil, M., Ijaz, M., and Khan, M. (2012). Evaluating the drought stress tolerance efficiency of wheat (Triticum aestivum L.) cultivars. Russian Journal of Agricultural and Socio-Economic Sciences 12.

Sallaku, G., Sandén, H., Babaj, I., Kaciu, S., Balliu, A., and Rewald, B. (2019). Specific nutrient absorption rates of transplanted cucumber seedlings are highly related to RGR and influenced by grafting method, AMF inoculation and salinity. Scientia horticulturae 243, 177-188.

Sereshti, H., Poursorkh, Z., Aliakbarzadeh, G., Zarre, S., and Ataolahi, S. (2018). An image analysis of TLC patterns for quality control of saffron based on soil salinity effect: A strategy for data (pre)processing. Food chemistry 239, 831-839.

Serra, F., Fogliatto, S., Milan, M., De Palo, F., Ferrero, A., and Vidotto, F. (2018). Effect of salinity on germination and growth of Echinochloa crus-galli and Oryza sativa. In "18th European Weed Research Society Symposium" New approaches for smarter weed management"", pp. 198-198. Kmetijski inštitut Slovenije.

Shewry, P. R. (2009). Wheat. Journal of experimental botany 60, 1537-1553.

Singh, G., and Patidar, S. (2018). Microalgae harvesting techniques: A review. Journal of environmental management 217, 499-508.

Vahtmäe, E., Kotta, J., Orav-Kotta, H., Kotta, I., Pärnoja, M., and Kutser, T. (2018). Predicting macroalgal pigments (chlorophyll a, chlorophyll b, chlorophyll a+ b, carotenoids) in various environmental conditions using high-resolution hyperspectral spectroradiometers. International journal of remote sensing 39, 5716-5738.

Yang, C., Zhao, L., Zhang, H., Yang, Z., Wang, H., Wen, S., Zhang, C., Rustgi, S., von Wettstein, D., and Liu, B. (2014). Evolution of physiological responses to salt stress in hexaploid wheat. Proceedings of the National Academy of Sciences 111, 11882-11887.

Zahra, S. M., Wahid, A., Maqbool, N., and Ibrahim, M. H. (2018). Effect of Thiourea on Physiological Performance of Two Salt Affected Rice (Oryza sativa L.) Cultivars. Annual Research \& Review in Biology, 1-10.

Zubair, M., Shakir, M., Ali, Q., Rani, N., Fatima, N., Farooq, S., Shafiq, S., Kanwal, N., Ali, F., and Nasir, I. A. (2016). Rhizobacteria and phytoremediation of heavy metals. Environmental Technology Reviews 5, 112-119.

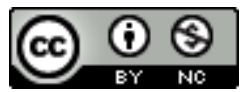

Open Access This article is licensed under a Creative Commons Attribution 4.0 International License, which permits use, sharing, adaptation, distribution and reproduction in any medium or format, as long as you give appropriate credit to the original author(s) and the source, provide a link to the Creative Commons licence, and indicate if changes were made. The images or other third party material in this article are included in the article's Creative Commons licence, unless indicated otherwise in a credit line to the material. If material is not included in the article's Creative Commons licence and your intended use is not permitted by statutory regulation or exceeds the permitted use, you will need to obtain permission directly from the copyright holder. To view a copy of this licence, visit http://creativecommons.org/licen ses/by/4.0/.

(C) The Author(s) 2021 